Effect of Ni precursor solution concentration on the magnetic properties and exchange bias of $\mathrm{Ni}-\mathrm{NiO}$ nanoparticulate systems

Aparna Roy', J. A. De Toro, V. S. Amaral, D. P. Marques, and J. M. F. Ferreira

Citation: Journal of Applied Physics 116, 093906 (2014); doi: 10.1063/1.4894629

View online: http://dx.doi.org/10.1063/1.4894629

View Table of Contents: http://aip.scitation.org/toc/jap/116/9

Published by the American Institute of Physics

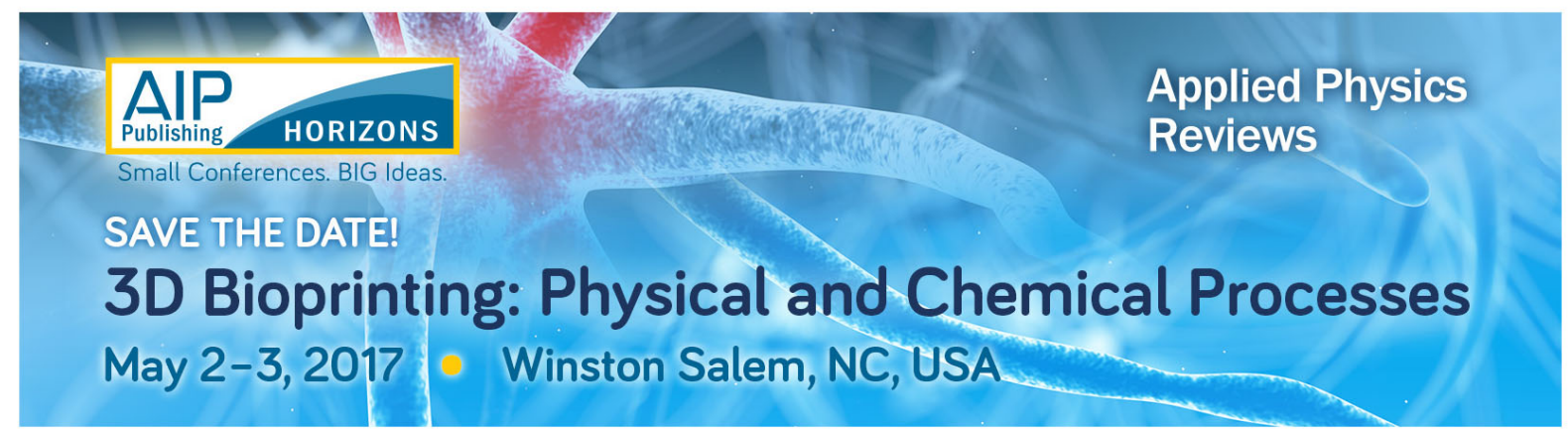




\title{
Effect of Ni precursor solution concentration on the magnetic properties and exchange bias of $\mathrm{Ni}-\mathrm{NiO}$ nanoparticulate systems
}

\author{
Aparna Roy, ${ }^{1, a)}$ J. A. De Toro, ${ }^{2}$ V. S. Amaral, ${ }^{3}$ D. P. Marques, ${ }^{2}$ and J. M. F. Ferreira ${ }^{1}$ \\ ${ }^{1}$ Department of Materials and Ceramics Engineering, CICECO, University of Aveiro, 3810193 Aveiro, \\ Portugal \\ ${ }^{2}$ Departamento de Física Aplicada, Universidad de Castilla La Mancha, 13071 Ciudad Real, Spain \\ ${ }^{3}$ Department of Physics, CICECO, University of Aveiro, 3810193 Aveiro, Portugal
}

(Received 16 July 2014; accepted 23 August 2014; published online 4 September 2014)

\begin{abstract}
We report on a comparative study of the exchange bias effect and magnetic properties of $\mathrm{Ni}-\mathrm{NiO}$ nanoparticulate systems synthesized by the chemical reduction of $\mathrm{NiCl}_{2}$ solution of two different molar concentrations $1 \mathrm{M}$ (high) and $0.05 \mathrm{M}$ (low) followed by annealing of the dried precipitate in the temperature range $400600^{\circ} \mathrm{C}$ in air. Interestingly, the samples derived from the low molarity solution have higher Ni content and larger crystallite size than those prepared from their high molarity counterparts. These molarity dependent features subsequently modulate the magnitude of the exchange bias field in the samples, which is found to be absent or small in the $0.05 \mathrm{M}$ series, but of moderate value in the $1 \mathrm{M}$ samples. The different physical attributes of the particles derived from different concentrations of Ni-precursor solution are explained by invoking different nucleation kinetics and supersaturation degrees surrounding the viable growing nucleus. Furthermore, an observed increase of exchange bias with increasing annealing temperature, in contrast to the reported agglomeration of particles on annealing and subsequent reduction in bias magnitude, has been explained in correlation to the Ni-NiO interface density. (C) 2014 AIP Publishing LLC.

[http://dx.doi.org/10.1063/1.4894629]
\end{abstract}

\section{INTRODUCTION}

Magnetic nanoparticles (NPs) have been the subject of intensive research over the past two decades due to their rich physical properties and extensive prospects for electronic and magnetic device applications. The study of exchange biased NPs, in particular, has gained increasing interest because of their promising technological applications as magnetic recording media or as possible flux amplifiers for magnetic resonance settings. ${ }^{1}$ An archetypal exchange biased nanoparticulate system is composed of a ferromagnetic (FM) and an antiferromagnetic (AFM) component coupled to each other via exchange interactions at the FM AFM interface. After cooling down below the Neel temperature of the AFM in a field high enough to saturate the FM, the interfacial exchange interaction favours only one mutual orientation of the FM and AFM spins, rendering it harder for the FM spins to rotate in one direction of an applied magnetic field than in the opposite one. ${ }^{2} \mathrm{~A}$ unidirectional exchange anisotropy is thus induced by the AFM into the FM, manifested as a shift of the hysteresis loop along the field axis, generally in a direction opposite to the cooling field. The magnitude of the shift, $\mathrm{H}_{\mathrm{E}}$, is known as exchange bias (EB) field. Apart from technological applications, investigation of exchange anisotropy in systems of reduced dimensions is of much fundamental interest due to the complex dependence of the EB effect on various factors such as size of the FM and AFM components, spin configuration at the FM AFM interface, interface disorder, i.e.,

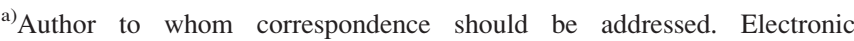
addresses: aparna.roy@ua.pt and aparnaroy15@gmail.com
}

roughness/crystallinity at the interface, anisotropy of the AFM, cooling field, ${ }^{3}$ content of FM and AFM phases, ${ }^{3,4}$ etc. In case of chemically prepared fine particles, concentration of the reactants becomes an important parameter controlling EB since the content and size of the FM component is likely to be dependent on the reactant concentration.

$\mathrm{Ni}-\mathrm{NiO}$ nanoparticulate systems have often been used for studies of exchange bias since the high Neel temperature of $\mathrm{NiO}(523 \mathrm{~K})$ makes them suitable for such studies over a wide temperature range, $5523 \mathrm{~K}$. Tuning the EB in these systems by altering preparation parameters, or the synthesis method altogether, has been the main objective of these investigations. Interesting and varied results were obtained. For example, Nogués et al. ${ }^{5}$ reported EB in Ni-NiO nanocomposites prepared by ball milling pure $\mathrm{NiO}$ powders in $\mathrm{H}_{2}$ atmosphere at room temperature. They obtained a room temperature EB value of $10 \mathrm{Oe}$. Del Bianco et al. ${ }^{6}$ studied the EB effect in Ni-NiO nanogranular samples prepared by mechanical milling of $\mathrm{NiO}$ in air followed by partial $\mathrm{H}_{2}$ reduction at different temperatures. In all their samples, EB vanished at $\sim 200 \mathrm{~K}$. Johnston-Peck et al. ${ }^{7}$ reported structural and magnetic studies on $\mathrm{Ni}$ (core)/ $\mathrm{NiO}$ (shell) nanoparticles of core diameter $824 \mathrm{~nm}$ and shell thickness $23 \mathrm{~nm}$ prepared by ligand chemistry and solution phase oxidation. They did not observe EB in any of their samples even at temperatures as low as $2.5 \mathrm{~K}$. Roy et al. observed $\mathrm{EB}^{8}$ above the superparamagnetic blocking temperature of $\mathrm{NiO}$ in $\mathrm{Ni}-\mathrm{NiO}$ nanoparticulate systems prepared by chemical reduction.

In this paper, we report on the role played by concentration of Ni-precursor solution in modulating the exchange bias and magnetic properties of $\mathrm{Ni}-\mathrm{NiO}$ nanoparticulate systems. 
Two different concentrations of the precursor solution, namely, $0.05 \mathrm{M}$ and $1 \mathrm{M}$ have been used. It is found that samples prepared from the low concentration solution have large $\mathrm{Ni}$ content, big crystallite size, and display small EB in comparison to those obtained from their high concentration counterparts. The physical attributes of the former samples stem from the influence of the precursor solution concentration on the kinetics of nucleation and growth of the solid nanoparticles. ${ }^{9,10}$ Other features such as a vertical shift of the magnetization in field cooled $\mathrm{M}-\mathrm{H}$ loops and an increase of exchange bias with increasing annealing temperature are also observed and explained in relation to the sample nanostructure.

\section{EXPERIMENTAL DETAILS}

Fine particles of $\mathrm{Ni}$ were prepared by chemically reducing the nickel salt $\mathrm{NiCl}_{2} \cdot 6 \mathrm{H}_{2} \mathrm{O}$ (nickel chloride hexahydrate, Sigma Aldrich, Germany) with sodium borohydride $\left(\mathrm{NaBH}_{4}\right.$, Alfa Aesar, Germany) as reducing agent. The volumes of $\mathrm{NiCl}_{2}$ solution used were $2000 \mathrm{ml}$ and $250 \mathrm{ml}$ for the $0.05 \mathrm{M}$ and $1 \mathrm{M}$ samples, respectively. In both cases, the concentration of $\mathrm{NaBH}_{4}$ solution was kept at $1 \mathrm{M}$. This was added dropwise at room temperature to the $\mathrm{NiCl}_{2}$ solution, over a period of $2 \mathrm{~h}$ under constant magnetic stirring. An instantaneous exothermic reaction ensued with the formation of a black precipitate and evolution of $\mathrm{H}_{2}$ gas. On completion of reaction, the precipitate was filtered and washed thoroughly with distilled water several times to remove all residual ions from the reaction mixture. It was then left for drying in an oven at $40^{\circ} \mathrm{C}$ for one week. The dried powder, called "asprepared" sample, was annealed in air at different temperatures in the range $300650^{\circ} \mathrm{C}$ at intervals of $50^{\circ} \mathrm{C}$, for $1 \mathrm{~h}$, to study the evolution of $\mathrm{Ni}$ and $\mathrm{NiO}$ phases. The annealed samples are denoted as $S_{300}, S_{350}, S_{400}$, etc., with the suffix indicating annealing temperature.

Crystalline structure and phase evolution of the annealed samples were studied by X-ray diffraction using a Rigaku Geigerflex DMax III/C X-ray diffractometer with filtered $\mathrm{Cu}$ $\mathrm{K}_{\alpha}$ radiation of wavelength $1.5406 \AA$. Microstructure was studied with a Hitachi H9000 transmission electron microscope (TEM). The magneto-thermal behavior, i.e., the fieldcooled (FC)/zero-field-cooled (ZFC) data was recorded in the temperature range $5300 \mathrm{~K}$ with a vibrating sample magnetometer (Cryogenics, UK), and for some samples, with a SQUID magnetometer in the temperature range $5390 \mathrm{~K}$. The exchange bias measurements were done with an EverCool MPMS SQUID magnetometer (Quantum Design) at $5 \mathrm{~K}$, upon cooling from $390 \mathrm{~K}$ (the highest accessible temperature) in a magnetic field of $50 \mathrm{kOe}$.

We mention here that for clarity of understanding, the annealing temperatures will be expressed in degree Celsius $\left({ }^{\circ} \mathrm{C}\right)$ and the temperatures related to magnetic measurements, in Kelvin (K).

\section{RESULTS AND DISCUSSION}

\section{A. X-ray diffraction and microstructure}

Figure 1 shows the X-ray diffraction (XRD) profiles of both series of samples annealed in the temperature range
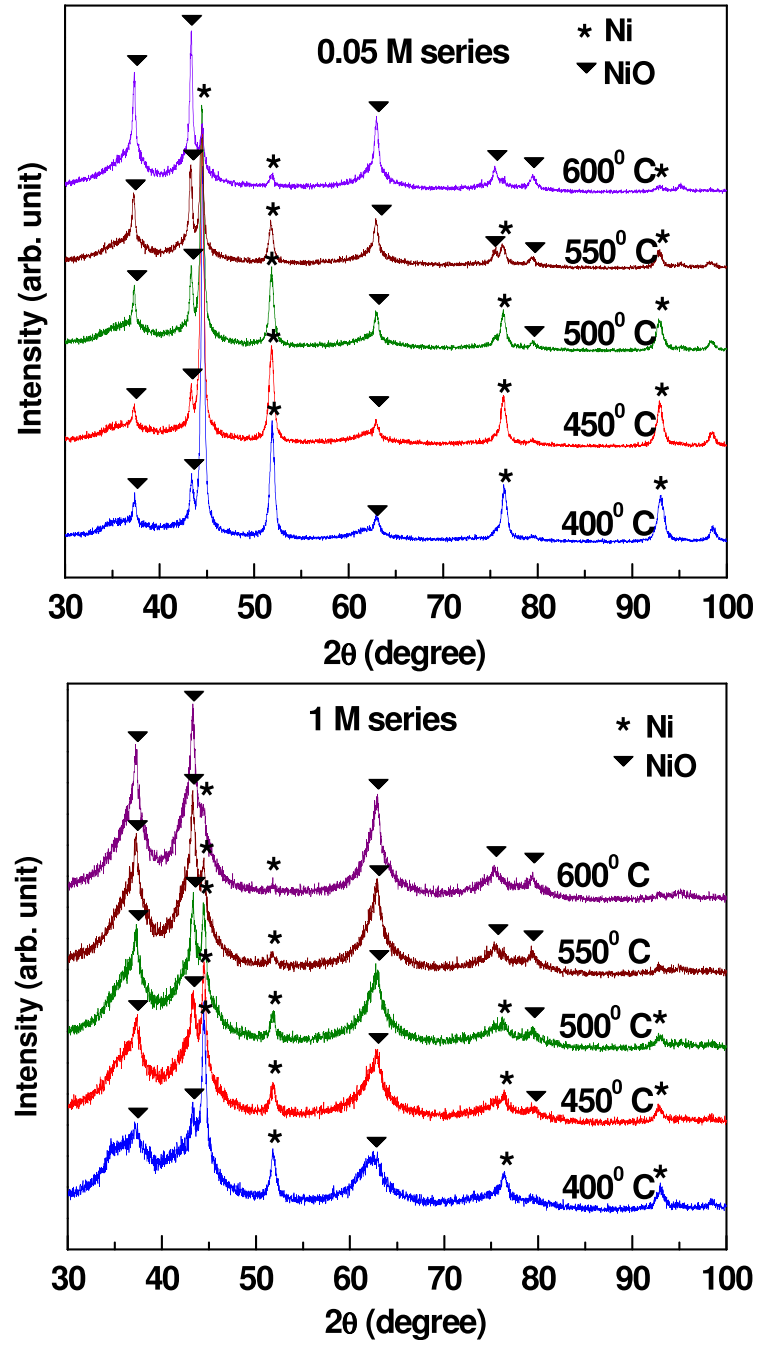

FIG. 1. X ray diffraction patterns of the samples, with corresponding annealing temperature mentioned adjacent to each pattern.

$400600^{\circ} \mathrm{C}$. All samples contain both $\mathrm{Ni}$ and $\mathrm{NiO}$ with the expected reduction of $\mathrm{Ni}$ content with air annealing. Samples annealed at 300,350 , and $650^{\circ} \mathrm{C}$ are not shown here since they do not contain both phases. Intense and sharp peaks of $\mathrm{Ni}$ are observed in the diffractograms of $0.05 \mathrm{M}$ series, whereas broad and comparatively less intense peaks are evidenced in the $1 \mathrm{M}$ series profiles. The intense Ni peaks in the former samples are indicative of high Ni content, while the sharpness of these peaks points to a large crystallite size of $\mathrm{Ni}$. The NiO peaks appear much diminished, implying small content of this phase.

In contrast, broad peaks in the diffractograms of $1 \mathrm{M}$ samples are suggestive of small size of both $\mathrm{Ni}$ and $\mathrm{NiO}$ phases. Furthermore, the NiO peaks are much more prominent and of higher intensity as compared to $0.05 \mathrm{M}$ series. Crystallite size of $\mathrm{Ni}$ in the $0.05 \mathrm{M}$ samples as calculated from XRD line broadening using the Scherrer approximation is on an average $16 \mathrm{~nm}$, while for the $1 \mathrm{M}$ series, the $\mathrm{Ni}$ and $\mathrm{NiO}$ sizes are 12.5 and $3.5 \mathrm{~nm}$, respectively. The sizes do not change significantly upon annealing. We were unable to extract a reliable estimation of the crystallite size of $\mathrm{NiO}$ for samples $0.05 \mathrm{M} \mathrm{S}_{400} \mathrm{~S}_{550}$ since the much diminished peaks gave poor results on fitting a Lorentzian distribution function 


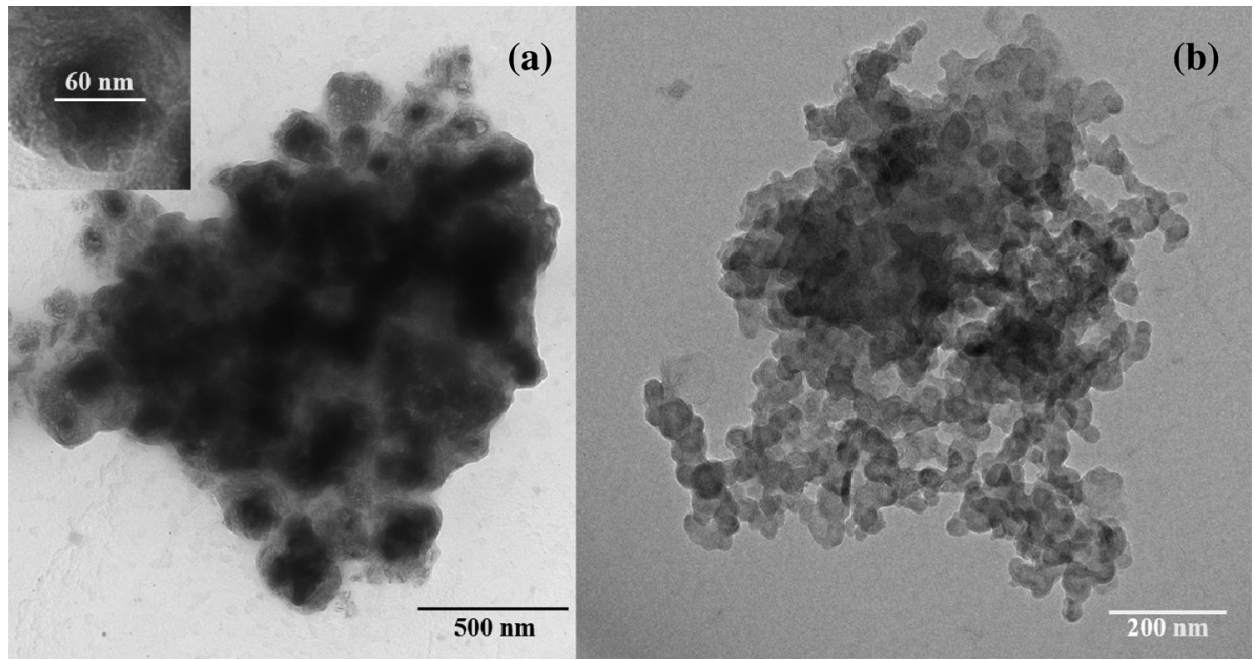

FIG. 2. TEM micrographs of samples from both series. (a) $0.05 \mathrm{M} \mathrm{S}_{500}$. The inset shows an enlarged view of a rep resentative core shell particle of ap proximate core size $60 \mathrm{~nm}$. (b) $1 \mathrm{M}$ $\mathrm{S}_{400}$, with particles of size $45 \mathrm{~nm}$.

to them. However, for $0.05 \mathrm{M} \mathrm{S}_{600}$, a similar fit yielded $15 \mathrm{~nm}$ as the $\mathrm{NiO}$ crystallite size.

Figure 2 displays the TEM micrographs of a sample each from either series, namely, $0.05 \mathrm{M} \mathrm{S}_{500}$ and $1 \mathrm{M} \mathrm{S}_{400}$. Dark regions against a light background are evidenced in the first micrograph, the former representing $\mathrm{Ni}$ and the latter signifying NiO. The particles seem to have a core-shell like morphology as highlighted in the inset with an approximate core size of $60 \mathrm{~nm}$, though at certain places they appear agglomerated. Figure 2(b) shows the micrograph of sample $1 \mathrm{M} \mathrm{S}_{400}$. Much smaller particles of size of about $45 \mathrm{~nm}$ are observed.

The reason for obtaining sharp and intense peaks in the XRD profiles of the samples of the $0.05 \mathrm{M}$ series may be explained considering the effect of the supersaturation degree of the Ni-precursor solution on the kinetics of nucleation and growth of particles precipitated from the solutions. A high supersaturation degree (1 M series) favours the formation of a large number of viable nuclei that will dispute the available ionic species for growing, resulting in the formation of particles having small sizes, and hence, a relatively high specific surface area. Oppositely, under a low supersaturation degree $(0.05 \mathrm{M}$ series $)$, the number of nuclei formed is less, allowing the ionic species to grow around the nucleus without much obstruction. However, the ions have to travel over longer diffusion paths to be added to the growing nuclei, resulting in slower growing kinetics of the few nuclei. This imparts them (growing nuclei) ample time to organize into a well defined crystalline structure. This is to say that besides being smaller, the nanoparticles derived from the $1 \mathrm{M}$ series are also expected to exhibit a more disordered crystalline structure in comparison to those of the $0.05 \mathrm{M}$ series, as confirmed by XRD analysis.

The different Ni particle sizes resulting from different concentrations of starting $\mathrm{Ni}$-precursor solution are then expected to result in $\mathrm{Ni}-\mathrm{NiO}$ composite structures with dissimilar fractions of non-oxidized/oxidized matter upon annealing in air, since oxidation will be more efficient in the samples with higher surface to volume ratio. In other words, the concentration of the Ni-precursor solution is expected to affect the functional properties of the synthesised $\mathrm{Ni}-\mathrm{NiO}$ nanoparticles.

\section{B. Magnetic properties}

Figure 3 shows the temperature dependence of the magnetization in three representative samples, namely, $0.05 \mathrm{M}$ $\mathrm{S}_{500}, 0.05 \mathrm{M} \mathrm{S}_{600}$, and $1 \mathrm{M} \mathrm{S}_{500}$. The data were recorded
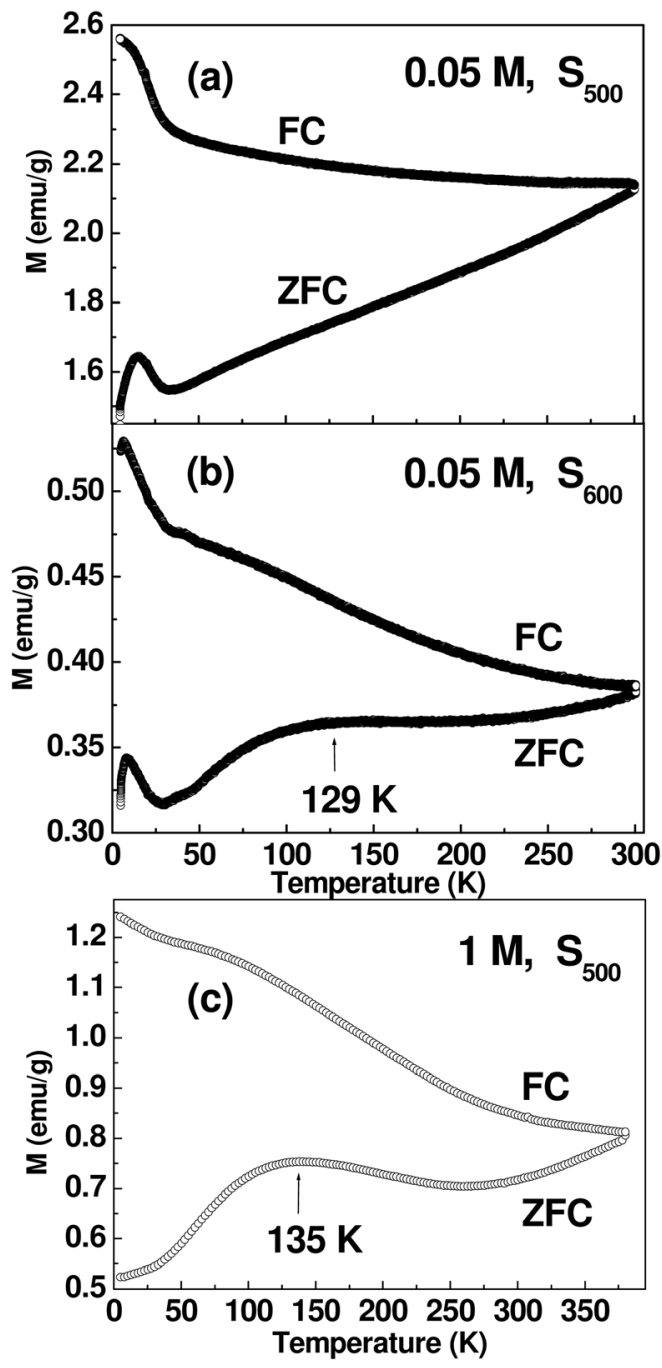

FIG. 3. Temperature dependence of the field cooled (FC) and zero field cooled (ZFC) magnetization, measured in an applied field of $300 \mathrm{Oe}$. 
following standard zero-field cooling and field cooling protocols under an applied magnetic field of $300 \mathrm{Oe}$ from $5 \mathrm{~K}$ to $300 \mathrm{~K}$ ( $390 \mathrm{~K}$ for the $1 \mathrm{M}$ series). For all samples, irreversibility in the FC and ZFC magnetization is observed right from $300 \mathrm{~K}$ ( $390 \mathrm{~K}$ for the $1 \mathrm{M} \mathrm{S}_{500}$ sample), the highest temperature of measurement. This (beyond) room temperature irreversibility has been attributed to the blocked state of the $\mathrm{Ni}$ particles considering the fact that real particulate systems invariably have a distribution in the size of their particles such that some large particles ${ }^{11}$ can always be present, which remain blocked at room temperature (RT, $300 \mathrm{~K}$ ), giving rise to FC/ZFC irreversibility. The fraction of such large Ni particles is very high in the $0.05 \mathrm{M}$ samples.

In addition to the RT irreversibility, some low temperature features are also observed. These include (i) a small peak at around $18 \mathrm{~K}$ in the $0.05 \mathrm{M}$ samples, (ii) a welldefined peak at $129 \mathrm{~K}$ in $0.05 \mathrm{M} \mathrm{S}_{600}$, and (iii) a pronounced peak at $135 \mathrm{~K}$ in $1 \mathrm{M} \mathrm{S}_{500}$. The peaks in the vicinity of $130 \mathrm{~K}$ have been identified as the superparamagnetic (SPM) blocking temperature of the $\mathrm{NiO}$ phase in the samples. ${ }^{8}$ No such peak is observed in $0.05 \mathrm{M} \mathrm{S}_{500}$, reflecting once again the low $\mathrm{NiO}$ content in this sample in conformity with XRD results. It is worth mentioning here that whereas a peak corresponding to the blocking of NiO NPs is observed in the M$\mathrm{T}$ plots of $1 \mathrm{M}$ samples right from $\mathrm{S}_{450}$ (not shown here), a similar peak for the $0.05 \mathrm{M}$ series appears only for sample $\mathrm{S}_{600}$, pointing out the difficulty of oxidizing the $0.05 \mathrm{M}$ (larger) $\mathrm{Ni}$ particles in comparison to the (smaller) particles obtained from the $1 \mathrm{M}$ solution.

Regarding the low temperature peak at $18 \mathrm{~K}$ in the ZFC magnetization of the $0.05 \mathrm{M}$ samples, AC susceptibility measurements in the vicinity of this peak can shed light on its origin. Figure 4 displays the real component of AC susceptibility $\left(\chi^{\prime}\right)$ for $0.05 \mathrm{M} \mathrm{S}_{500}$ measured as a function of temperature, in the range $535 \mathrm{~K}$, for different frequencies of the driving AC field. A very low frequency sensitivity of the peak at $\sim 20 \mathrm{~K}$ is evidenced, suggestive of some phase transition and ruling out any kind of particle blocking. In line with

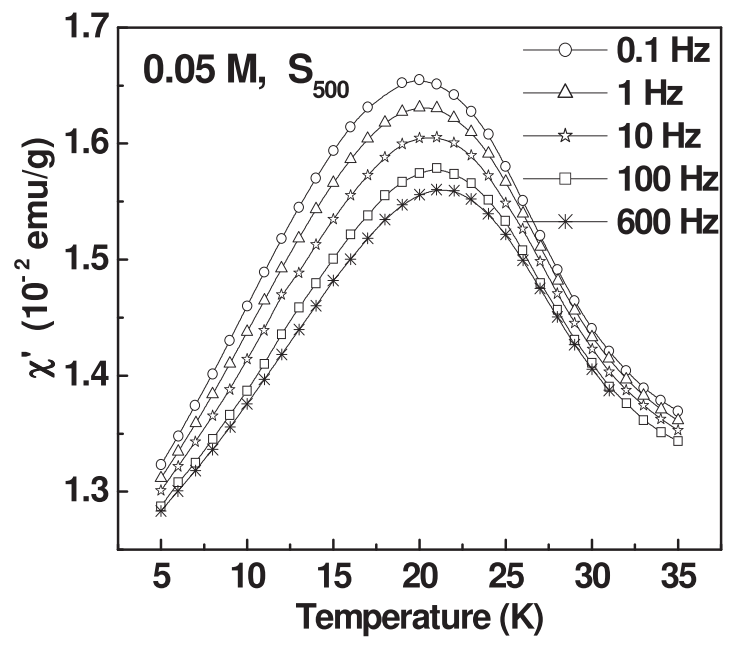

FIG. 4. Temperature dependence of the real component $\chi^{\prime}$ of ac susceptibil ity of sample $0.05 \mathrm{M} \mathrm{S}_{500}$, measured at five different frequencies of the applied oscillating field (amplitude 2Oe). The peak temperature is barely affected by the excitation frequency. some of our earlier findings on Ni nanoparticles prepared by the borohydride reduction method, ${ }^{12}$ it is proposed that this peak reflects a Curie-like transition in oxygen-stabilized tetragonal $\mathrm{Ni}(\mathrm{t}-\mathrm{Ni})$. Although the tetragonal phase of $\mathrm{Ni}$ is expected to get almost completely converted to fcc $\mathrm{Ni}$ on heat treating the as-prepared sample at and above $400{ }^{\circ} \mathrm{C}$, small traces of this phase are possibly left in the $0.05 \mathrm{M}$ samples, not clearly discernible by XRD but leaving its finger print on the more sensitive magneto-thermal behaviour. In contrast, sample $1 \mathrm{M} \mathrm{S}_{500}$ does not evidence any trace of t$\mathrm{Ni}$, either in XRD profile or in M-T plot as expected from its lower Ni content.

Figure 5 portrays the RT $(300 \mathrm{~K}) \mathrm{M}-\mathrm{H}$ plots of samples $\mathrm{S}_{500}$ and $\mathrm{S}_{600}$ of both molarities. A near saturation of the magnetization is observed for $0.05 \mathrm{M} \mathrm{S}_{500}$, once again hinting at the existence of large Ni particles in the sample since the magnetization of large particles is more like the magnetization of a bulk material. For $\mathrm{S}_{600}$, however, a pronounced non-saturating component is observed in the $\mathrm{M}-\mathrm{H}$ plot, corroborating the presence of a substantial $\mathrm{NiO}$ fraction with its typical linear AFM response. A similar non-saturating component of magnetization is observed in the M-H plots at RT (still below the Neel temperature of $\mathrm{NiO}$ ) of not only $\mathrm{S}_{600}$ but all samples of the $1 \mathrm{M}$ series, commensurate with their appreciable NiO (AFM) content. The fit in Figure 5(c) is discussed in Sec. III C.

\section{Exchange bias}

Figure 6 displays the M-H plots at $5 \mathrm{~K}$ for samples $\mathrm{S}_{550}$ and $\mathrm{S}_{600}$ of both series, measured after cooling from $390 \mathrm{~K}$, down to the measuring temperature in an applied magnetic field of $50 \mathrm{kOe}$. The left panel shows the complete loop, while an expanded view of each loop is displayed on the right one. The loops are shifted from the zero field position

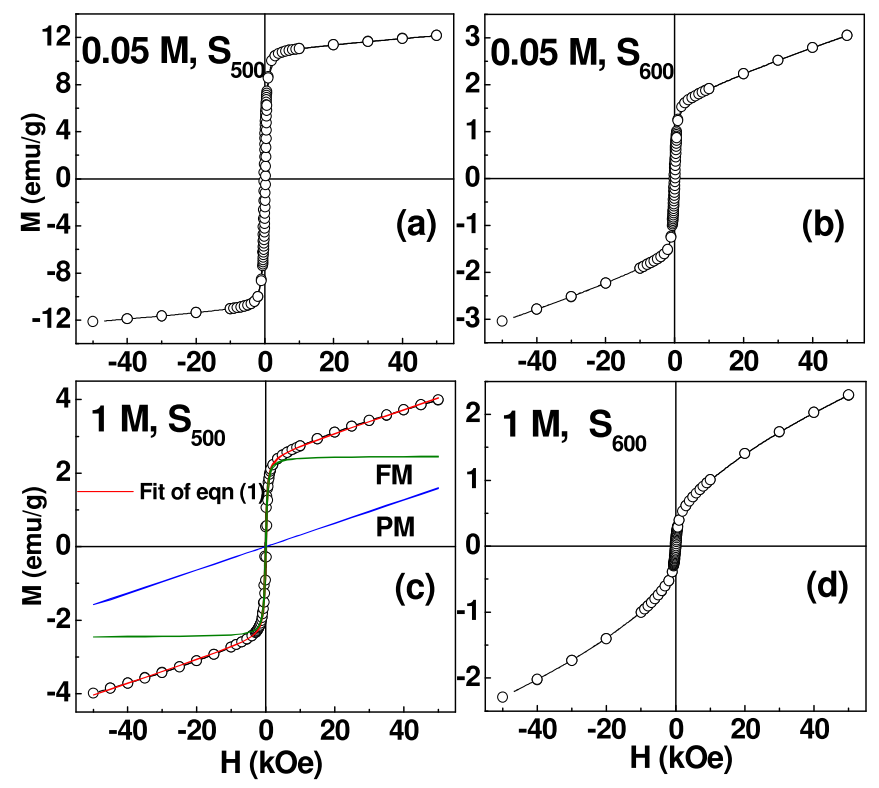

FIG. 5. Hysteresis loops measured at $300 \mathrm{~K}$ of samples $\mathrm{S}_{500}$ and $\mathrm{S}_{600}$ of both $0.05 \mathrm{M}$ and $1 \mathrm{M}$ series. Figure 5(c) also shows the fit of Eq. (1) to the total magnetization of the sample, along with the separated FM and PM components. 

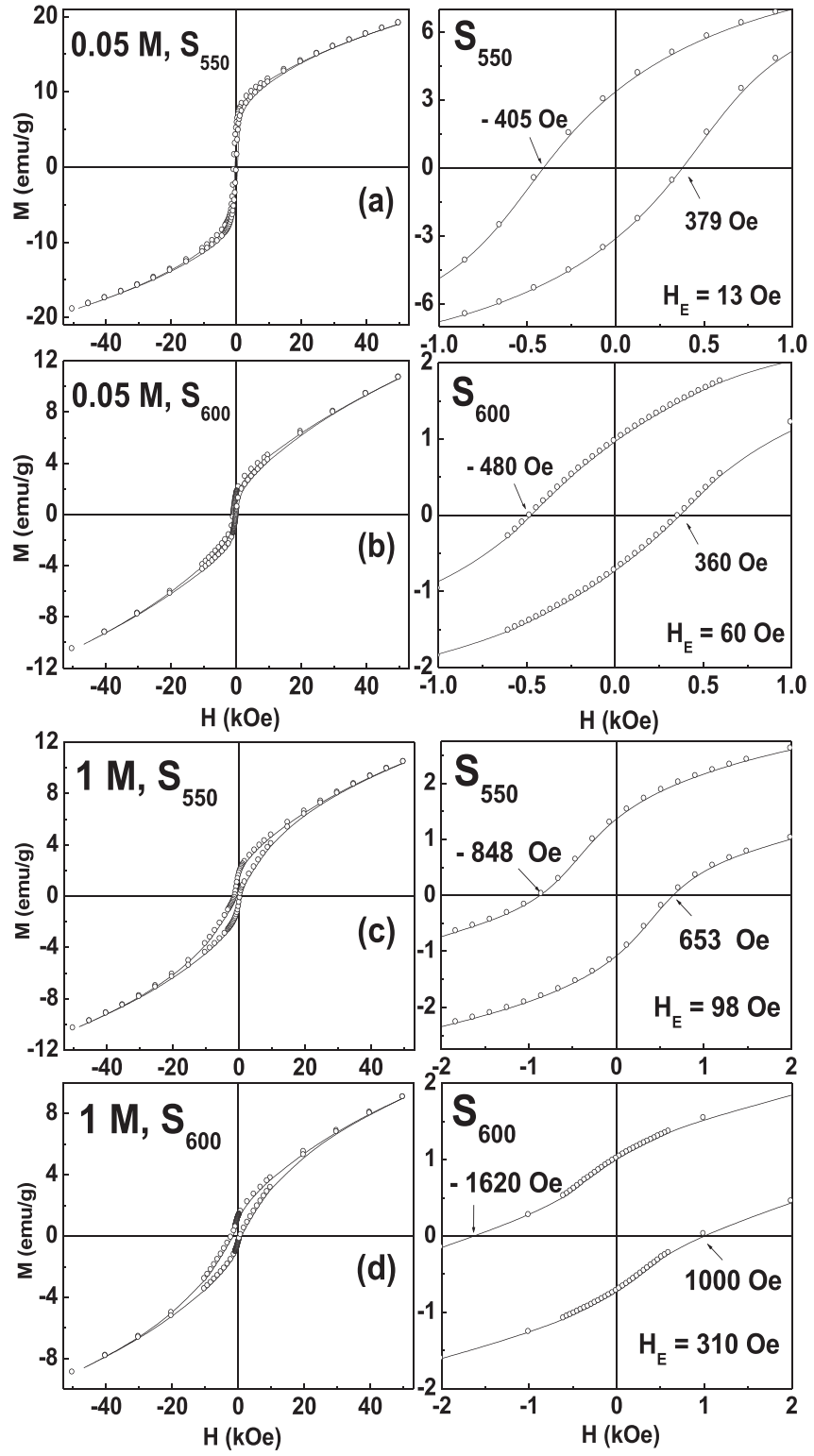

FIG. 6. M H loops of selected samples measured at $5 \mathrm{~K}$, after cooling from $390 \mathrm{~K}$ in a field of $50 \mathrm{kOe}$. Coercivities of the left and right branches of the loops are marked on each loop.

to the left, confirming the existence of exchange bias. Table I shows the percentage of $\mathrm{Ni}$ by weight, and the EB field, $\mathrm{H}_{\mathrm{E}}$, at $5 \mathrm{~K}$ for both series of samples. The Ni weight $\%$ has been calculated from the saturation magnetization, $\mathrm{M}_{\mathrm{S}}$, obtained from the fit of RT $(300 \mathrm{~K})$ loops to the equation ${ }^{13}$

$$
M(H)=\frac{2 M_{S}}{\pi} \tan 1\left[\frac{H \pm H_{C}}{H_{C}} \tan \left(\frac{\pi}{2} S\right)\right]+\chi H .
$$

The first term is customarily used to fit FM hysteresis loops while the second term accounts for a paramagnetic (PM) component, with $\mathrm{H}_{\mathrm{C}}, \mathrm{S}$, and $\chi$ representing respectively, the coercivity, squareness of the hysteresis loop and the paramagnetic susceptibility. Note that there is no EB at RT to affect the fitting to the above field-symmetric function. The absence of room temperature bias may stem from the fact that the field cooling of samples was done from $390 \mathrm{~K}$ (Ref. 14) and not from $523 \mathrm{~K}$, the Neel temperature of NiO. A fit
TABLE I. Percentage by weight of $\mathrm{Ni}$ in the samples and exchange bias field " $\mathrm{H}_{\mathrm{E}}$ " at $5 \mathrm{~K}$. The $\mathrm{M}_{\mathrm{S}}$ values shown are at $300 \mathrm{~K}$, obtained from the fit of RT loops to Eq. (1).

\begin{tabular}{|c|c|c|c|c|c|c|c|}
\hline \multicolumn{4}{|c|}{$0.05 \mathrm{M}$ series } & \multicolumn{4}{|c|}{$1 \mathrm{M}$ series } \\
\hline Sample & $\begin{array}{c}\mathrm{M}_{\mathrm{S}} \\
(\mathrm{emu} / \mathrm{g})\end{array}$ & $\begin{array}{c}\text { Ni fraction } \\
\% \mathrm{w}\end{array}$ & $\begin{array}{l}\mathrm{H}_{\mathrm{E}} \\
(\mathrm{Oe})\end{array}$ & Sample & $\begin{array}{c}\mathrm{M}_{\mathrm{S}} \\
(\mathrm{emu} / \mathrm{g})\end{array}$ & $\begin{array}{c}\text { Ni fraction } \\
\% \mathrm{w}\end{array}$ & $\begin{array}{l}\mathrm{H}_{\mathrm{E}} \\
(\mathrm{Oe})\end{array}$ \\
\hline $\mathrm{S}_{400}$ & 18.61 & 34.21 & 0 & $\mathrm{~S}_{400}$ & 4.98 & 9.16 & 16 \\
\hline $\mathrm{S}_{450}$ & 15.27 & 28.08 & 0 & $\mathrm{~S}_{450}$ & 3.34 & 6.14 & 38 \\
\hline $\mathrm{S}_{500}$ & 11.15 & 20.51 & 0 & $\mathrm{~S}_{500}$ & 2.46 & 4.53 & 46 \\
\hline $\mathrm{S}_{550}$ & 7.13 & 13.12 & 13 & $\mathrm{~S}_{550}$ & 1.2 & 2.2 & 98 \\
\hline$S_{600}$ & 1.71 & 3.14 & 60 & $S_{600}$ & 0.673 & 1.24 & 310 \\
\hline
\end{tabular}

of Eq. (1) to the RT M-H plot of one of the samples, $1 \mathrm{M}$ $\mathrm{S}_{500}$, and the separated FM and PM components is shown in Figure 5(c). Similar fits have been obtained for all samples.

The small magnitude of $\mathrm{H}_{\mathrm{E}}$ in the samples is attributed to both the small anisotropy of $\mathrm{NiO}\left(\mathrm{K}_{\mathrm{NiO}}=2.8 \times 10^{6} \mathrm{erg} /\right.$ $\mathrm{cm}^{3}$ ) and the reduced FM AFM interface area. Existence of large particles in a size distribution reduces the FM AFM interface density. As uncompensated spins housed at the interface are the ones responsible for $\mathrm{EB},{ }^{15,16}$ a reduction in their number due to reduced interface area, results in a concomitant reduction of EB in the system. An inspection of the $\mathrm{H}_{\mathrm{E}}$ values also shows that for all annealing temperatures, the $0.05 \mathrm{M}$ samples display considerably less bias as compared to their $1 \mathrm{M}$ counterparts, indicating their comparatively low $\mathrm{Ni}-\mathrm{NiO}$ interface area.

A second observation from Table $\mathrm{I}$ is the increase of $\mathrm{H}_{\mathrm{E}}$ with annealing temperature. This is in contrast to reported behavior, ${ }^{17,18}$ where with increasing heat treatment temperature, agglomeration of particles is observed to cause reduction in the magnitude of EB. However, the reverse observation in our samples may stem from the increase in $\mathrm{NiO}$ content and, hence, of the Ni-NiO interface area. This is further ratified by Figure 7, which shows a plot of $\mathrm{H}_{\mathrm{E}}$ as a function of the reciprocal of $\left(f_{\mathrm{Ni}}\right)^{1 / 3}$, where $\mathrm{f}_{\mathrm{Ni}}$ is the volume fraction of $\mathrm{Ni}$. All, except one, data points, be they from the $0.05 \mathrm{M}$ series or $1 \mathrm{M}$ series fall well within a linear trend, emphasizing that the relevant parameter controlling $\mathrm{EB}$ is the $\mathrm{Ni} / \mathrm{NiO}$ ratio and thus the Ni particle size, no matter where the sample comes from.

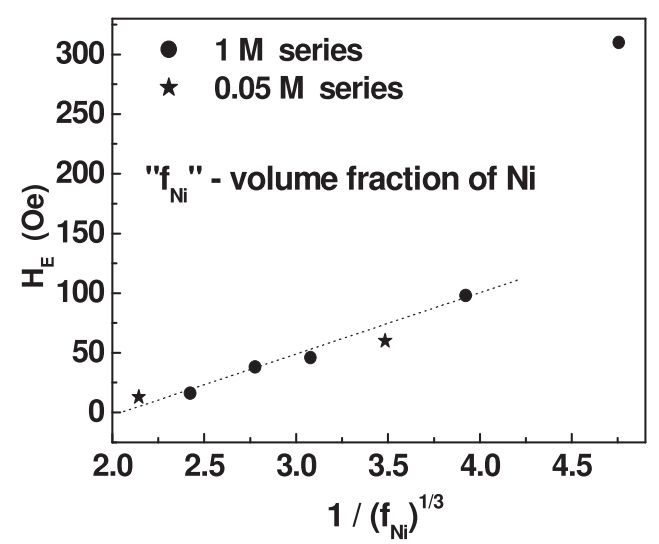

FIG. 7. Exchange bias field, $\mathrm{H}_{\mathrm{E}}$, as a function of the reciprocal of $\left(\mathrm{f}_{\mathrm{Ni}}\right)^{1 / 3}$, where $f_{N i}$ is the volume fraction of Ni. The graph reflects the $1 / d_{F M}$ depend ence of $\mathrm{H}_{\mathrm{E}}$. 
This linear dependence of the bias field on $1 /\left(\mathrm{f}_{\mathrm{Ni}}\right)^{1 / 3}$ reflects the basic EB rule (see Ref. 19): " $H_{E} \propto \frac{1}{d_{F M}}$ ", stemming from the interface nature of exchange coupling, ${ }^{2} \mathrm{~d}_{\mathrm{FM}}$ being the size of a FM region. The only data point falling way out of the trend is that for $1 \mathrm{M} \mathrm{S}_{600}$, which suggests that, besides size effects, the interface microstructure is different (more disordered) in this most oxidized sample of the two series.

Coming back to Figure 6, other features observed apart from horizontal loop shifts are: (i) the vertical shift of the hysteresis loop, i.e., a shift of the M-H loop along the magnetization axis, for samples $0.05 \mathrm{M} \mathrm{S}_{600}, 1 \mathrm{M} \mathrm{S}_{550}$, and $1 \mathrm{M} \mathrm{S}_{600}$, and (ii) an increasing coercivity, $H_{C}$, with increasing bias field, $H_{E}$, for all samples. As regards the first feature, the loops are shifted upwards by $2.87,2.6$, and $3.87 \%$, respectively, of their saturation magnetization at $5 \mathrm{~K}^{20}$ The magnitude and direction of the magnetization shift depend strongly on the cooling field, microstructure of the AFM, and the nature of the coupling (FM or AFM) at the interface. ${ }^{21}$ A positive magnetization shift (e.g., along the cooling field direction) as in the investigated samples implies that some of the spins are fixed or frozen in the direction of the cooling field and cannot be reversed by any field. These frozen spins at the origin of the vertical shift are typically uncompensated AFM spins at the FM-AFM interface, i.e., the very same spins giving rise to exchange bias. Our results roughly agree (given the concurrent change in particle size) with the expected correlation between exchange bias and vertical shift the samples with the highest $\mathrm{H}_{\mathrm{E}}$ also display the highest vertical shift.

The second feature observed in Figure 6, namely, higher $\mathrm{H}_{\mathrm{C}}$ in samples with higher $\mathrm{H}_{\mathrm{E}}$, (considering, for example, the $1 \mathrm{M}$ samples) is yet another finger print of exchange coupling. It is well known that the coercivity of monodomain FM particles decreases with decreasing particle size (in our case, upon increasing oxidation). ${ }^{22}$ Given the fact that the size of the Ni region in the $1 \mathrm{M}$ series is always below the critical size for the multi-to-monodomain crossover $(55 \mathrm{~nm}),{ }^{5}$ their progressive oxidation should result in a reduction of coercivity. The observation of the opposite trend, however, $\left(\mathrm{H}_{\mathrm{C}}\right.$ increases from 751 Oe in sample $1 \mathrm{M} \mathrm{S}_{550}$ to $1310 \mathrm{Oe}$ in $\mathrm{S}_{600}$ ) emphasizes that the coercivity of the Ni regions is governed by the exchange coupling with $\mathrm{NiO}$, which completely over runs size effects.

\section{CONCLUSIONS}

In summary, we have studied the exchange bias effect in $\mathrm{Ni}-\mathrm{NiO}$ nanoparticulate systems prepared by the borohydride reduction of Ni-precursor solution of two different molar concentrations. Remarkably, the low concentration solution results in samples having high Ni content and larger Ni particles in comparison to samples with relatively low $\mathrm{Ni}$ content and small $\mathrm{Ni}$ particles obtained from the higher concentration solution. This is explained on the basis of the effect of the supersaturation degree of the Ni-precursor solutions on the kinetics of nucleation and growing process of precipitated particles. The different particle sizes derived from the different concentrations of starting Ni-precursor solution lead to the formation of Ni-NiO core-shell like structures with dissimilar fractions of non-oxidized/oxidized matter upon annealing in air, affecting their functional properties. Accordingly, the EB values exhibited by the $0.05 \mathrm{M}$ series of samples are of small magnitude as compared to $1 \mathrm{M}$ series. Thus, a variation in the concentration of $\mathrm{Ni}$ precursor solution provides a simple way of tuning exchange bias in $\mathrm{Ni}-\mathrm{NiO}$ nanoparticles synthesized via this chemical route.

\section{ACKNOWLEDGMENTS}

A. Roy acknowledges the Foundation of Science and Technology (FCT) of Portugal for financial support under the Grant SFRH/BPD/77574/2011. D. P. Marques acknowledges financial support from the Brazilian CNPQ. Support from CICECO, University of Aveiro, and from the Spanish CICYT [Project MAT2011-26207] is gratefully acknowledged.

${ }^{1}$ M. Barbic and A. Scherrer, Solid State Nucl. Magn. Reson. 28, 91 (2005).

${ }^{2}$ J. Nogues and I. K. Schuller, J. Magn. Magn. Mater. 192, 203 (1999).

${ }^{3}$ J. Sort, J. Nogues, X. Amils, S. Surinach, J. S. Munoz, and M. D. Baro, Appl. Phys. Lett. 75, 3177 (1999).

${ }^{4}$ J. Sort, J. Nogues, X. Amils, S. Surinach, J. S. Munoz, and M. D. Baro, J. Magn. Magn. Mater. 219, 53 (2000).

${ }^{5}$ J. Nogues, V. Langlais, J. Sort, S. Doppiu, S. Surinach, and M. D. Baro, J. Nanosci. Nanotechnol. 8, 1775 (2008).

${ }^{6}$ L. D. Bianco, F. Boscherini, A. L. Fiorani, M. Tamisari, F. Spizzo, M. V. Antisari, and E. Piscopiello, Phys. Rev. B 77, 094408 (2008).

${ }^{7}$ A. C. Johnston Peck, J. Wang, and J. B. Tracy, ACS Nano 3(5), 1077 (2009).

${ }^{8}$ A. Roy, J. A. De Toro, V. S. Amaral, P. Muniz, J. M. Riveiro, and J. M. F. Ferreira, J. Appl. Phys. 115, 073904 (2014).

${ }^{9}$ J. R. Frade, J. Mater. Sci. 28, 6715 (1993).

${ }^{10}$ R. Lacmann, A. Herden, and C. Mayer, Chem. Eng. Technol. 22(4), 279 (1999).

${ }^{11}$ For Ni NPs to remain blocked at $\mathrm{T}_{\mathrm{B}} \quad 300 \mathrm{~K}$, their size as estimated from the equation $\mathrm{K}_{\mathrm{Ni}} \times \mathrm{V} \quad 25 \mathrm{~K}_{\mathrm{B}} \mathrm{T}_{\mathrm{B}}$ should be $\geq 34 \mathrm{~nm}$ [Ref. 5]. Here, $\mathrm{V}$ is the particle volume; $K_{\mathrm{B}}$ is the Boltzmann constant; $\mathrm{K}_{\mathrm{Ni}} 5 \times 10^{4} \mathrm{erg} / \mathrm{cm}^{3}$ is the anisotropy of $\mathrm{Ni} ; \mathrm{T}_{\mathrm{B}}$ is the blocking temperature.

${ }^{12}$ A. Roy, V. Srinivas, J. A. De Toro, and J. P. Goff, Phys. Rev. B 74, 104402 (2006).

${ }^{13}$ M. B. Stearns and Y. Cheng, J. Appl. Phys. 75, 6894 (1994).

${ }^{14}$ Exchange bias values of 610 Oe were obtained at $300 \mathrm{~K}$ [Ref. 8] for sam ples measured with a vibrating sample magnetometer having a maximum attainable temperature of $490 \mathrm{~K}$. This allowed the field cooling of samples from $490 \mathrm{~K}$ close to $523 \mathrm{~K}$ which was instrumental in producing the above exchange bias fields at $300 \mathrm{~K}$.

${ }^{15}$ T. C. Schulthess and W. H. Butler, Phys. Rev. Lett. 81, 4516 (1998).

${ }^{16}$ H. Ohldag, A. Scholl, F. Nolting, E. Arenholz, S. Maat, A. T. Young, M. Carey, and J. Stohr, Phys. Rev. Lett. 91, 017203 (2003).

${ }^{17}$ Yong Goo Yoo, Nam Seok Park, Seong Gi Min, and Seong Cho Yu, J. Magn. 10(4), 133 (2005).

${ }^{18}$ T. Yu, H. Naganuma, W. X. Wang, Y. Ando, and X. F. Han, J. Appl. Phys. 111, 07D908 (2012).

${ }^{19}$ The volume fraction of $\mathrm{Ni}, f_{N i}$, is expressed as: $f_{N i} \frac{N V_{N i}}{\left(N V_{N i}\right)+\left(N^{\prime} V_{N i O}\right)}$ $\left(\frac{N}{V_{T}}\right) V_{N i}$, where $V_{N i}\left(V_{N i O}\right)$ is the volume of an average $\mathrm{Ni}(\mathrm{NiO})$ region and $\mathrm{N}\left(\mathrm{N}^{\prime}\right)$ is the number of such regions. $V_{N i}$ will be proportional to $f_{N i}$ if both (i) the number of $\mathrm{Ni}$ regions and (ii), the total volume, $V_{T}$, remain con stant. The first condition is fulfilled in a process of "progressive oxidation" as a means to vary the $\mathrm{Ni}$ concentration (as in the present investigation), which will mainly reduce the size of the non oxidized Ni particles $\left(V_{N i}\right)$ but not their number $(N)$. As for the sample total volume, $V_{T}$, it will always increase due to the incorporation of oxygen (i.e., due to the lower density of $\mathrm{NiO}$ compared to $\mathrm{Ni}$ ). However, for low Ni concentrations (which is the case for the investigated samples), high relative variations in the volume of metallic $\mathrm{Ni}, N V_{N i}$, can be achieved with relatively little addition of oxygen; therefore, the variations of $\mathrm{V}_{\mathrm{T}}$ can be neglected. Thus, for our samples, we can write $f_{N i} \propto V_{N i} \propto d_{F M}^{3}$, where $d_{F M}$ is the typical diameter of a Ni region, 
whereby plotting as a function of $1 /\left(f_{N i}\right)^{1 / 3}$ is expected to be equivalent to plotting $v s 1 / d_{F M}$.

${ }^{20}$ The percentage of this vertical shift has been estimated from the formula $\frac{\left(M_{S}^{+}-M_{S, \text { avg }}\right)}{M_{S, q v g}} \times 100$, where $M_{S}^{+}$is the positive saturation and $M_{S, \text { avg }}$ is the av erage of the positive and negative saturations. $M_{S}^{+}$and $M_{S}^{-}$have been obtained as fitting parameters (intercepts on the magnetization axis) of lin ear fits to the high field magnetization values of the loops.

${ }^{21}$ J. Nogues, C. Leighton, and I. K. Schuller, Phys. Rev. B 61, 1315 (2000).

${ }^{22}$ B. D. Cullity and C. D. Graham, Introduction to Magnetic Materials, 2nd ed. (John Wiley and Sons, Inc., New Jersey, 2009), Chap. 11, p. 361. 